\section{¿DE QUÉ HABLAMOS CUANDO HABLAMOS DE LITERATURA DEL EXILIO REPUBLICANO DE 1939?}

\author{
Francisco Caudet \\ Universidad Autónoma de Madrid
}

\section{WHAT ARE WE TALKING ABOUT WHEN WE TALK ABOUT THE LITERATURE OF THE REPUBLICAN EXILE OF 1939?}

\begin{abstract}
What are we referring to when we talk about the republican literary exile in 1939? It is possible to segregate this literature from that revolution and from the people that fought for this to become a reality and that suffered so much, the hardship, the death and the exile?

The exile is a sub-culture that can be difficultly integrated in the culture of the acceptance country.

During Franco's dictatorship it is necessary to consider three different literatures: the literature which was close to the political regime, the one that showed some "cracks" in the regime -we are referring to existentialism and alarmism in the 1940's decade, a kind of literature which started it own breaking-off the regime by the 1950's decade-and finally the literature in the exile. It is necessary to ask if it is correct to write the history of the Spanish literature in the post-war period from an exclusive point of view and to take into consideration a questionable territoriality. As soon as possible it is essential accepting and admitting that the history of the Spanish literature if badly written and badly told.
\end{abstract}

KEY WORDS: Historical oblivion; historical memory; fascism; exile literature; association for the recovering of the historical memory; friends of the ones who fell for the freedom.

Al hilo del verso de Arturo Serrano Plaja, "Mirando en la memoria las señales...", argumentaba yo, en un artículo de 1999 (Ínsula 18), que ese verso me resultaba más fructífero, y más cargado de sentido y de razón, que este otro, "Hacer de olvido un pacto a la memoria", de la "Elegía a la ausencia de la patria" de Enríquez Gómez (Guillén 102). Cuando se trata del olvido histórico, esta última opción en absoluto ha de ser la única opción, y ni siquiera una opción. Porque de ser así estariamos nuevamente ejerciendo una forma de violencia, en este caso contra la memoria histórica -en la que se ha de incluir la memoria personal y la colectiva (Halbwach)-. Max Aub, en "Franco en la UNESCO", artículo publicado en 1953, decía:

La actualidad es gran comedora. Sin embargo, el hombre lo es porque, entre otras cosas, no olvida. Pero la política le lleva
RESUMEN: ¿De qué hablamos cuando hablamos del exilio literario republicano de 1939? ¿Se puede segregar esa literatura de esa revolución y del pueblo que por hacerla realidad luchó y sufrió toda suerte de penalidades, la muerte y el exilio?

El exilio es una subcultura que difícilmente se integra en la cultura del país de acogida.

En los tiempos de la dictadura franquista cabe partir de la existencia de tres literaturas: la afín al sistema, la que entrevé grietas en el sistema, existencialismo y tremendismo de los años 40, y que a partir de 1950 empezó la ruptura con el régimen; y la literatura del exilio. Habría que plantearse si es válido escribir la historia de la literatura española de posguerra desde el exclusivismo de una equívoca territorialidad. Urge reconocer y aceptar que la historia de la literatura española a partir de 1939 está mal historiada, mal narrada.

PALABRAS CLAVE: Olvido histórico; memoria histórica; fascismo; exilio; literatura del exilio; asociación para la recuperación de la memoria histórica; amigos de los caídos por la libertad.

mil veces a borrar palabras y hechos de la memoria porque ésa es la medida de las conveniencias. Los buenos políticos suelen tener mala memoria; mas el escritor vive de ella y por ella se hace. Divergencia fundamental que puede explicar el fracaso de tantos escritores, si lo son de veras, metidos a políticos. Las obras sólo quedan de la voz de la fama; y nosotros luchamos contra el olvido. Los políticos llegan al recuerdo -que es la Historia- a fuerza, muchas veces, de lo que llaman contemporizar; es decir, ser contemporáneo, olvidar lo pasado con tal de asegurar el paso inmediato, transigir, condescender, mentir. No son estas prendas del escritor, como no sea por juego (Hablo como hombre 134).

Ese "contemporizar", ese "olvidar lo pasado con tal de asegurar el paso inmediato, transigir, condescender, mentir", 
que Aub adscribe a los políticos, es aplicable, aunque sólo sea de manera parcial, al pacto de olvido sobre el que se ha construido - ¿era una necesidad o una claudicación?- la transición. Un pacto que, como el tiempo se está encargando de demostrar, viene vulnerando - ¿han sido y son amargos posos de tan larga derrota esos peajes del entreguismo posibilista?- el derecho y el deber de toda nación, del conjunto de la ciudadanía, a conocer su pasado. Un derecho y un deber que se conjugan perfectamente con la praxis socio-politica de construir el presente y el futuro sobre unas bases debidamente cimentadas. Paul Valéry había escrito en una ocasión: "Lo que más me llama la atención del acto de recordar no es el que repita lo ya ocurrido sino que sirve de alimento al presente." Y John Berger, por su parte, ha afirmado: "The past is not for living in; it is a well of conclusions we draw from in order to act" (Ways of seeing 11).

El profesor Manuel Tuñón de Lara, que pasó más de treinta años en el exilio, recordaba, en su "Última clase magistral", que para Bloch "la historia es la ciencia del devenir de los hombres en el tiempo, que viene de ayer y va hacia mañana"; y, a partir de esa definición, argumentaba que

para pensar en el mañana tenemos también que pensar en el ayer, conocer el ayer. Y necesariamente para eso los pueblos se ven obligados a recuperar su memoria colectiva cuando ésta, como ha habido casos, les ha sido arrebatada, ocultada o falsificada. Nosotros [los españoles] hemos pasado por eso como otros pueblos, como el pueblo alemán, como ha pasado con los países del Este, etc. (De la Granja 454).

Pero España presenta, no es menos cierto, unas variantes tan peculiares y distintivas que hacen que su caso no sea del todo equiparable al de esos otros pueblos. La principal de esas variantes es que en España triunfó, en 1939, el fascismo del nacional-catolicismo y se mantuvo, durante cuarenta años, en el poder. Esta variante vulneró en su momento, y lo sigue haciendo hasta hoy, la función -según Tusell- de la memoria "como elemento que configura espiritualmente una sociedad, $y$, además, es indicio de los cambios que en ella se producen". Y añadía Tusell a continuación:

Un ejemplo muy obvio es el de la guerra civil española. Su recuerdo contribuyó durante años al mantenimiento del régimen franquista, incluso, por paradójico que parezca, en una parte de los vencidos. Con el paso del tiempo, sin em- bargo, la memoria de la guerra civil sirvió de acicate para la transición cuando actuó como una especie de espada de Damocles sobre la clase política, recordándole que se podia producir una recaída en un conflicto civil como el de los años treinta (Tusell 2002).

Por contra, en la Europa donde el fascismo fue derrotado, "la memoria colectiva fundamental ha sido la del antifascismo y la de la victoria de 1945; ambas han permitido una configuración de la unidad política cuyas consecuencias vivimos en el año 2002" (Tusell 2002).

Desde la perspectiva de un país vencido, decía Günter Grass en "Recuerdo..." esto que sigue, que ni siquiera mínimante se plantean los vencedores y verdugos franquistas de otrora, ni -esto es lo más grave, si cabe- sus últimos retoños, ahora que de facto ha sido vencida/sustituida la dictadura por una cada vez menos bisoña democracia que se va acercando más y más, aunque con sus escollos, a los principios del viejo republicanismo:

Recordar es arduo sobre todo para la generación de más edad. Tal vez por eso se nos ha ocurrido a nosotros los alemanes la nueva expresión "labor de recordar", típica y enfatizadora de un lugar común. Se reclama como confesión de culpa, se rehusa como insolencia y se cumple con empeño, porque desde hace décadas, cada vez que el pasado nos vuelve a dar alcance, se absuelve como un ejercicio obligatorio, y, desde los años sesenta, también por parte de las sucesivas generaciones que entonces eran jóvenes, las que se supondrian libres de cargos. Es como si los hijos y los nietos quisieran recordar en nombre de sus callados padres y abuelos. Hoy en día no pasa una semana en que no se prevenga contra el olvido. Una vez que, como se esperaba, hemos recordado bastante a menudo el número tan alto de judios perseguidos, exiliados, asesinados, recordamos tarde la deportación y el asesinato de decenas de miles de gitanos. Para muchos demasiado tarde, ahora estamos obligados a recordar el destino de cientos de miles de trabajadores forzados que llegaron de Polonia, de la Unión Soviética y de muchos otros paises y fueron colocados en las cadenas de montaje de la industria bélica alemana.

\section{Y poco más adelante añadía Günter Grass:}

A veces sucede que los extranjeros nos observan llaman suplicio autoinfligido a la actitud de los alemanes de recordar 
su pasado, con lo que de paso se dice también que nuestro recuerdo es un suplicio. Pero no se le ve venir el final. Cuando planeamos el futuro, el pasado ya ha dejado sus marcas de olor en tierra supuestamente virgen y ha hincado señales que remiten a tiempos dejados atrás.

Tras lo anterior, y a modo de conclusión, recordaba Günter Grass, en ese mismo artículo, que el escritor húngaro Gyorgy Konrad, poniendo la mirada en la historia de Europa, ha dicho: "Recordar es humano, podemos decir que es en sí lo humano".

Acaso sea así porque por encima de todo queremos ser acto y parte, o expectación de conseguir serlo, en un presente y en un futuro, que vienen de un ayer y que, como eslabones de una misma cadena, intuimos al alcance de nuestras manos. Necesitamos, ahora y siempre, atisbar un horizonte en el que nuestros deseos individuales y colectivos, privados y públicos, cuyas raíces se asientan en los predios de un largo ayer del que venimos, puedan tener cumplimiento en estas horas de hoy y en las de mañana y en las de otros muchos mañanas. Para ello, no podemos ni debemos contentarnos con un eslabón (Carnés). Queremos, en suma, tener, como esa zigzagueante y temblorosa flecha, a la que hace referencia Aristóteles en Ética Nicomáquea $(\mathrm{I}, 2)$, un objetivo, una finalidad, un sentido:

Si existe, pues, algún sentido (télos) de nuestros actos que queramos por sí mismo y lo demás por él, y no elegimos todo por otra cosa -porque así se seguirá hasta el infinito, de suerte que el deseo sería vacío y vano-, es evidente que ese sentido y plenitud será lo bueno y lo más excelente. $Y$ así, el saber esto, ¿no tendrá gran influencia en nuestra vida y como arqueros que saben también a dónde dirigen sus flechas no dirigiremos las nuestras hacia donde debemos?

El exilio es la quiebra del arco y de la flecha; y también del arquero, de lo que "podemos decir que es en sí lo humano".

Esa quiebra compendia, en el siglo $X X$, el gran efecto devastador del fascismo, efecto que perdura y envenena $y$ distorsiona y... neurotiza el hoy, este hoy español.

Esa trágica quiebra es todavía una herida del pasado que no parece tener cura. Pero la tiene. Con envidiable firmeza -envidiable firmeza porque no es un supuesto sobre el que hemos construido en España la transición-, Michelle Bachelet daba, al poco de ser elegida presidenta de Chile, una infalible receta: "Las heridas del pasado se curan con más verdad." Peter Brooks, en Psychoanalysis and Literature, coincidía con lo declarado por la nueva presidenta de Chile, y daba para ello este pequeño argumentario:

Mens sana in fabula sana: mental health is a coherent life story, neurosis is a faulty narrative. Such a premise closely resembles that of the detective story, which equates the incomplete, incoherent, baffling story with crime, whereas detection is the making of an intelligible, consistent, and unbroken narrative. "Thus have you reasoned it all out beautifully in one long chain!" Watson exclaims to Sherlock Holmes, quite typically, at the end of one of their cases. The narrative chain, with each event connected to the next by reasoned causal links, marks the victory of reason over chaos, of society over the aberrancy of crime, and restitutes a world in which aetiological histories offer the best solution to the apparently unexplainable.

En "Continuará...", el discurso de título alegórico que pronunció Günter Grass en Estocolmo en el acto de la entrega del Premio Nobel de Literatura 1999, sacó a colación la frase de Theodor Adorno: "Escribir un poema después de Auschwitz es algo bárbaro, y eso corroe también la conciencia de por qué se hizo imposible escribir hoy poemas..." Günter Grass explicó en esa ocasión su desacuerdo con Adorno, arguyendo que se podía y debía seguir escribiendo después de Auschwitz, convirtiendo la poesía o la prosa, como hizo él y su generación, "en memoria y sin dejar que el pasado acabase..." Sólo así "se pudo mantener abiertas las heridas y compensar el deseado y prescrito olvido con un tozudo 'Érase una vez..."' (Grass).

Estas palabras las podrian haber hecho suyas muchos escritores españoles sólo si en España hubiera sido derrotado, en 1939, el nacional-catolicismo. Como en España, a diferencia de en Alemania donde en 1945 fue derrotado el nacional-socialismo, no se dio esa condición, las conciencias críticas con el régimen franquista, que no fueron encarceladas -caso de Miguel Hernández- o asesinadas -caso de Federico García Lorca-, abandonaron el país, dando comienzo a un largo exilio. Desde ese momento, narrar las heridas y traumas de ese ayer se convirtió para ellos en una obligación y una necesidad inexcusables. Los que por diversas circunstancias permanecieron en el interior 
de España presos, en libertad condicional o en distintas formas de clandestinidad (Molina, Hermanos), sujeto todo el pais a un férreo control militar, tuvieron que dejar de escribir, o lo hicieron para, dentro de unos márgenes muy estrechos, dar testimonio de la realidad. En la España de posguerra son manifestaciones estéticas de esa angostura el tremendismo y el existencialismo, en novela (Martínez Cachero; Barrero); el garcilasismo, en poesía (De la Concha); y el posibilismo, en teatro (Caudet 1984).

También hubo quienes escribieron novela, poesía y teatro para lanzar salvas en honor del régimen (Caudet 1992).

Con independencia del género, cabe partir de la existencia, en los tiempos de la dictadura franquista, de tres literaturas. Dos en el interior: una, afín o cercana al sistema; $y$, otra, la que empezó a entrever, con las limitaciones estéticas del existencialismo o el tremendismo, algunas de las grietas de aquella España. Desde mediados de la década de 1950, una nueva generación de escritores empezó la ruptura con el régimen que apenas habian soñado, si es que tuvieron ese sueño, los tremendistas y existencialistas de la década de 1940 (Sobejano; Sanz Villanueva). La tercera es la literatura del exilio.

Importa destacar que esas tres literaturas tienen, a pesar de las diferencias que hay entre ellas, una historia común porque, a fin de cuentas, representan tres maneras de habérselas con la realidad española del momento. En la literatura del interior el "Érase una vez..." estaba fuertemente condicionado por la censura, aunque, en el caso de la literatura afín y/o servil a la dictadura, los escritores aceptaban, identificados con el régimen, las mediaciones y servidumbres que éste imponía. Pero, insisto, esas dos literaturas eran, cada una a su manera y con variaciones de importancia, expresión de aquella España que se haIlaba bajo el implacable control de un militar africanista (Balfour), cuyo régimen dictatorial difícilmente se le puede aplicar el calificativo, según la propugna Juan Linz, de régimen autoritario (Linz), ni parece ajustado a los hechos la manera en que lo describe el historiador Javier Tusell: "El 'franquismo' consiste [...] en una mentalidad que en esencia no es sino el resultado negativo de la experiencia republicana visto desde una óptica conservadora (en este sentido el régimen es, por excelencia, la anti-República" (Tusell 1975, 382). A las víctimas, así, se las culpabiliza. Hay muchas maneras de hacer la apología del franquismo.
0 simplemente, hay muchas maneras de distorsionar la realidad del franquismo, una brutal dictadura que lo fue desde el comienzo hasta el final. Paul Preston, en "La crisis política del régimen franquista", hace este balance de los últimos años del franquismo:

En los años siguientes al asesinato del almirante Carrero Blanco, llevado a cabo el 20 de diciembre de 1973, España experimentó un período de actividad política mucho más dramático del que fuera posible durante los treinta y cuatro años precedentes de la dictadura de Franco. Esto no significa, sin embargo, que se produjera un relajamiento de la maquinaria represiva del régimen. Por el contrario, a lo largo de los años 1974 y 1975, la represión bajo la forma de arrestos masivos, torturas y ejecuciones, así como la facilidad por parte de la policía y Guardia Civil en hacer uso de las armas, se incrementó hasta niveles nunca vistos desde la década de los cuarenta (Preston 11).

En la literatura del exilio se podía hablar en libertad del tiempo pasado, del "Érase una vez...", pero los escritores, como exiliados que eran, estaban excluidos del devenir de su pais, no eran ya parte del "Continuará...". Sus narraciones, poemarios, obras de teatro. Incluso ensayos, despojados de su espacio natural y condenados a ser un eslabón desprendido de la serie temporal, eran víctimas igualmente de esa grave, y por partida doble, mutilación.

Francisco Ayala argumentaba, en "La cuestionable literatura del exilio", esto que sigue que no solamente es aplicable a la literatura:

En cuanto a la novela del exilio... no se sabe qué hacer con ella. Quiero decir que los estudiosos, los historiadores y profesores que se ocupan de establecer panoramas de la literatura española (entiéndase, la de los territorios a que se extiende la soberanía del Estado español, segregada del cuerpo de las letras hispanas, forman la gran literatura española) hacen en sus esquemas un embarazoso apartado para meter ahí como en un ghetto las obras de los exiliados. El expediente es torpe y -supongo- insatisfactorio para quienes lo usan. Varios novelistas del exilio teníamos ya establecida una posición en las letras españolas antes de la guerra civil (a Sender, por ejemplo, se le había concedido el premio nacional de literatura); y algunos hemos vuelto a incorporarnos a la actividad literaria de este país con obras escritas y publicadas de nuevo aquí. 
Nuestra labor tiene una continuidad dentro de la cual el exilio constituye, en la particular experiencia de cada uno, una circunstancia vital que no parece justificar la exclusión de nuestro nombre del cuadro de la literatura contemporánea para arrinconarnos en una especie de lazareto (Ayala 1981).

Llegados a este punto, mi primera propuesta va dirigida a cuestionar la validez de iniciar la historia de la literatura de la posguerra con La familia de Pascual Duarte (1942), Hijos de la ira (1944) e Historia de una escalera (1947). Se comprende, aunque no es justificable, que durante la larga dictadura se fuera escribiendo la historia de la literatura a partir de la producción literaria realizada en el interior del país y hasta se comprende, aunque tampoco resulta justificable, que se valoraran como hitos, o marcadores decisivos, ciertas obras y fechas -en particular la novela, el libro de poesía y la obra de teatro que acabo de citar- en el contexto del desierto cultural en que aparecieron. Pero ya no se puede mantener más ese criterio como indisputable. Porque en el exilio, desde que terminó la guerra, se hizo novela, poesía y teatro y habría que plantearse si es válido escribir la historia de la literatura española de posguerra desde el exclusivismo de una equívoca territorialidad cuando muy bien, como es mi propuesta, la literatura española de la posguerra debe empezar a historiarse incluyendo -o incluso, sobre todo en los años cuarenta y cincuenta, desde y/o en función de la extraterritorialidad (Steiner 1977).

Para el estudio de la literatura española de 1939 en adelante resulta indispensable recuperar autores y obras fundamentales del exilio. Lo es porque sin esos autores y sus obras no se puede escribir la historia de la literatura española de ese período, ni de la que le precede ni de la que le sigue. La historia de la literatura española, cuando se empiece a prestar la debida tasa de atención a estas premisas -y ya es urgente que se haga-, se habrán de hacer nuevos planteamientos y no pocas rectificaciones. Urge, para empezar, reconocer y aceptar que la historia de la literatura española a partir de 1939 está mal historiada, mal narrada. Historiar y narrar, que es una y otra cosa lo mismo, exige relacionar todos los hilos sueltos y encontrar entre ellos las conexiones que les son esenciales. Es el paso previo al acto de historiar/narrar. Porque no hay otra manera de transmitir el significado de lo acaecido. Como dice John Berger en Another way of telling: "Meaning is discovered in what connects, and cannot exist without development. Without a story, without an unfolding, there is no meaning" (Berger 1995, 89).

Tal como está narrada la historia de la literatura española, que quedó por fuerza mayor desmembrada en 1939, hay un "development" y un "unfolding" pero se deja de lado -todavía cuarenta años después de haber muerto el dictador- una parte fundamental de "what connects". Las historias de esa literatura, que apenas toman en consideración a los autores del exilio, cuando lo hace es para utilizarlos con una finalidad torticera. No se ha planteado aún qué hacer con esos autores y se persiste en privilegiar a los del interior a costa de, desfigurando el todo, el conjunto.

Hay excepciones. A algunos autores del exilio se les ha incorporado a la historia de la literatura, pero como parte del canon ya establecido. Con esa vuelta al interior de algunos autores exiliados, en vez de cuestionar y problematizar el canon se le refuerza. Después de cuarenta años de haber muerto el dictador son convenientemente utilizados tales autores exiliados para dejar las cosas como estaban y como se pretende todavía que sigan estando.

A lo que se ve a nadie interesa reconocer -es la aplicación a la historia literaria y cultural de España del pacto de silencio sobre el que se sentaron las bases de la transición- la condición de literatura trunca que la guerra y el exilio impusieron a la literatura española. Pero este reconocimiento -acaso por eso hay tantas resistencias- es una premisa sine qua non para empezar a plantearse cómo pensar y escribir de otra manera la historia la literatura española. No se puede continuar dando como un hecho irrefutable que la literatura española reinició sin más, a los pocos años de haber terminado la guerra, su andadura y que lo hizo simplemente entroncando con su tradición -bien sea, la picaresca, el realismo barojiano o el garcilasismo-. Pasó ciertamente eso en la España pero no pasó sin más porque no es eso lo que pasó a toda la literatura española, en la que hay que incluir también a la que se estuvo haciendo en esos años fuera de España. Pretender, todavía hoy, que esa literatura no cuenta para nada, o es en el mejor de los casos una rama desgajada del tronco que quedó en España, es un despropósito académico que, de un lado, pone en evidencia una lamentable falta de criterios objetivos y científicos y, de otro, aboca a desterrar definitivamente de la historia literaria -y civil- de Espa- 
ña al grueso de los hombres de letras que tuvieron que abandonar el país. La partidista manera en que Marias y Bleiberg dejaron, a numerosos autores exiliados fuera de la primera edición Diccionario de Literatura (Bolinger), ha dado paso a la ausencia de criterio con que se continúan escribiendo, más de sesenta años después, la mayor parte de las historias literarias de ese período.

La política de la desmemoria y de la desinformación sobre el pasado persigue la meta última de evitar que la ciudadanía descubra los horrores del ayer, sean recordadas las víctimas, se les haga una debida restitución y se pase juicio a los verdugos. Con esa estrategia no se ha sido posible ni lo es aún partir del pasado para, desde él, encontrar los perfiles constitutivos de la cadena histórica.

Resulta más que previsible que a los exiliados y a las víctimas de la represión franquista les espere también en futuro, al menos en amplios sectores de la sociedad española, la misma suerte que a la Historia: grandes dificultades para que puedan ser incorporados, con todo lo que ello implica, a la cadena narrativa. Digo que es así al menos en amplios sectores de la sociedad española porque se está produciendo una brecha cada vez mayor entre lo que piensa una y otra parte de la ciudadanía. Progresivamente, el tema del exilio y de la represión cuenta ya con investigadores, en algunos casos trabajando en grupos, que se dedican cada vez con más ahínco a ambos temas, y porque han aparecido últimamente asociaciones de ciudadanos, como la Asociación para la Recuperación de la Memoria Histórica o "Amigos de los Caídos por la Libertad", que se están movilizando.

La obra literaria desarrollada en el exilio es, sobre todo después de la muerte de Franco, la que más posibilidades ha tenido de regresar e integrarse en España. Pero como una coartada, a menudo muy sutil. Muy sutil porque -lo apuntaba más arriba- regresa a España la obra literaria de algunos exiliados y se la incorpora al patrimonio cultural nacional $y$, en ese punto, se la desgaja del proyecto republicano y del grueso del exilio.

Política, literatura, sociología, formas de comportamientos y de mentalidades, oficios, profesiones, arte..., constituyen un conjunto -acaso porque son la misma cosa, o son expresiones de la misma cosa- que debe permanecer estrechamente relacionado y engarzado porque, en definitiva, ese conjunto define lo que es la cultura. Segregar una parte de ese conjunto, bien sea la literatura o el arte, es entender el concepto de cultura de manera sesgada.

Ferrándiz Alborz recordaba en 1957, en un artículo publicado en España Republicana de Buenos Aires, que "junto con los [sic] intelectuales, se expatrió una multitud de personas más humildes, obreros y labradores, que también representan una merma sensible para la nación." $Y$ a continuación añadía que era una grave equivocación dejar de lado este "aspecto del problema" o considerar "fuera de lugar relacionarlo con la cultura literaria, científica, artística". Entre otros motivos, seguía argumentando Ferrándiz Alborz, porque:

Una cultura no es sólo el libro que se escribe, el cuadro que se pinta, la escultura que se modela, la música que se compone, el fenómeno que se investiga, la clase que se desarrolla. Es también el campo que se ara, la casa que se levanta, el hierro que se forja, el motor que se mueve, etc. ("¿Qué será de España?").

Pero incluso cuando se persiste en sólo centrar la atención en lo estrictamente artístico-literario, de manera más genérica, la labor intelectual, y se recuerda -como hizo Francisco Ayala en 1949 (Ayala 1949)- que la falta de un público para quien escribir era uno de los motivos por los que resultaba tan sangrante y demoledor para los escritores vivir exiliados, esa constatación debería asimismo ser objeto -por las siguientes razones que aduce Ferrándiz Alborz en su artículo- de una adecuada contextualización:

En Europa y América son continuos los lamentos -justificados- sobre la situación de los intelectuales españoles, como si ellos fueran toda la cultura española, como si la cultura se mantuviera del aire y en el aire, sin una base social -realidad y circunstancia- de la cultura española. Y es esto precisamente lo que dramatiza más aún la situación de la cultura española.

El estudio de la obra literaria del exilio habría de hacerse, por ello, tomando en cuenta sus relaciones, o falta de relaciones, con esa base social. Tal estudio pondría sobre el tapete la cuestión, nada baladí, de si la literatura y esa base social, formada por más del noventa por ciento de exiliados eran parte del mismo exilio o eran dos exilios distintos, dos realidades separadas, sin apenas contacto. 
Si bien los escritores exiliados pretendian tener su base social, la de los exiliados y la de los paises que les dieron albergue, y mantenían además la ilusión de estar haciendo una obra de creación que en el futuro habría de integrarse en el legado cultural de una España igual o parecida a la que tuvieron que abandonar, lo cierto es que los escritores exiliados apenas tuvieron incidencia en esa base social que -insisto- estaba formada mayoritariamente por clases trabajadoras.

Pero esas clases sociales fueron su público durante la República y, sobre todo, durante la Guerra Civil (Salaün).

¿Qué había ocurrido para que en el exilio hubieran dejado de serlo? ¿Qué se hizo para que volvieran a serlo? ¿Puede darse la paradoja de que los intelectuales acabaron exiliando de su exilio a aquellas clases que representan el grueso del exilio? ¿0 acaso terminaron exiliándose a sí mismos de esas clases que compartían con ellos la misma condición de exiliados y los mismos horizontes de restaurar en España la República?

Estos interrogantes me llevan a hacerme la pregunta, no menos grave y no menos difícil de responder, de si no estaremos los estudiosos del exilio literario republicano exiliando al grueso del exilio no literario por no ser exilio literario. Por otra parte, si continuamos estudiando la obra literaria del exilio solamente como obra literaria, me temo que terminaremos exiliando la literatura del exilio del proyecto republicano.

A la fecha, el exilio republicano es un valor políticamente en alza siempre y cuando sirva para legitimar la transición. El exilio republicano es un valor a la baja, y de él se desentienden los políticos y sus gestores culturales, si cuestiona o pone en entredicho esa necesidad. Es un valor en alza honrar a los grandes escritores del exilio pero quitando hierro a su condición de exiliados y olvidando su condición de republicanos. El énfasis se pone en las maravillas de su arte de escribir, en la españolidad de ese arte, en incorporar ese arte al canon de las letras hispanas. Así va convirtiendo el poder a esos autores en una coartada (Ayala 1981).

Ese discurso olvida, de manera interesada -hay también mucha ignorancia, el mundo académico es en España lo que es..., duro es decirlo y más admitirlo-, que ese arte se creó en una situación histórica límite y que no se puede segregar de esa situación, que cabe calificar de genocidio. Importa y mucho, claro está, recuperar el corpus literario que, a pesar de todo, llegaron a crear unos autores de excepción, pero ese arte nunca debería ser utilizado para, de una u otra forma, contribuir a legitimar una situación histórica, la transición.

Ni tampoco debería ser instrumentalizado para olvidar que el exilio republicano de 1939 fue un exilio de intelectuales y de clases medias y trabajadoras, estando unos y otros unidos en el mismo proyecto de cambiar en profundidad las estructuras sociales, políticas, económicas y culturales del país. Ese proyecto fue masacrado y continúa, para todos los efectos, en el exilio. Reintegrarlo plenamente y con todas las consecuencias a la sociedad española actual, equivaldría a reconstruir la historia de esa masacre, recordar a los culpables y reparar, aunque solamente sea nombrando a las víctimas y a los verdugos, los daños históricos.

Esa historia debe necesariamente incluir -es otra de mis propuestas- a los que sufrieron el exilio exterior y el exilio interior. Son dos caras de la misma moneda y a esas dos caras el franquismo las persiguió con la misma saña.

En 1939 tuvieron que abandonar el pais a la fuerza -no se exilia nadie por voluntad propia- unos 250.000 republicanos y en el interior, entre 1939 y 1945, fueron fusilados o murieron en la cárcel aproximadamente el mismo número de presos políticos. Las cifras de la represión franquista en los primeros años de la posguerra oscilan en torno a un número de víctimas no inferior a 150.000. Ésta es la cifra que baraja Hartmut Heine (Heine 1990, 309). Rafael Abella, por su parte, señala en Por el Imperio hacia Dios:

Tan sólo hay un dato -que damos con ciertas reservasproporcionado por el Ministerio de Justicia que habla de 192.684 personas "ejecutadas o muertas en prisión"; entre 1939 y 1944, lo que deja la incógnita de óbitos debidos a una u otra causa (Abella 56).

El profesor Fontana, que destaca de la represión franquista su naturaleza y función política, baraja unas estadísticas de ejecuciones que evidencian que predominaron "de manera aplastante los campesinos y obreros". (Fontana 24).

A la tragedia de cerca de 200.000 exiliados hay que sumar la tragedia de las víctimas de la represión en el interior 
de España, que se acerca a los 200.000, e incluso supera esa cifra de fusilados si se le añade la de presos políticos del franquismo que murieron en la cárcel, como ocurrió con Miguel Hernández, de hambre y enfermedades (Casanova).

Todo ese pasado no se puede borrar con un pacto de silencio. Esa imposibilidad hace a su vez inviable que sobre ese pacto se pueda construir un nuevo proyecto de pais. Porque ese pacto, legitimador de ese nuevo proyecto -la llamada transición-, está construido sobre unas bases ilegítimas.

Hace poco, Emilio Silva, presidente de la Asociación para la Recuperación de la Memoria Histórica, escribía en El País:

El proceso de recuperación de la memoria y del conocimiento de la dura realidad de la guerra civil y del franquismo evidencia la necesidad que tiene la sociedad española de conocer su historia reciente. El impacto causado por la exposición sobre el exilio, realizada recientemente en Madrid (Exilio 2002), la apertura de las fosas comunes o el documental sobre los niños secuestrados a las presas republicanas, es un reflejo del desconocimiento generalizado de esa parte de la historia. Amplios sectores sociales se encuentran sorprendidos por lo que están conociendo, y los que ya lo conocian y lo padecieron están necesitados de reconocimiento, de ver ese reflejo de sus vidas en espacios públicos. Si no seguimos el proceso de países como Alemania o Francia en la revisión del pasado relacionado con el fascismo, y no se habla y se cambia el significado de ese pasado y de nuestra relación con él, seguirán en nuestra identidad y habitando en nuestro inconsciente colectivo efectos que causó directamente la dictadura (Silva).

A continuación, Emilio Silva denunciaba que uno de los efectos del pacto político de no revisar el pasado ha sido la pérdida de la memoria histórica, lo cual ha afectado particularmente a las nuevas generaciones de españoles:

Decenas de miles de jóvenes españoles no han estudiado en sus centros de enseñanza ni la Segunda Repúblíca, ni la guerra civil, ni la dictadura franquista. Es posible que la causa sea lo extenso de los programas académicos pero, ¿qué jóvenes está educando nuestra sociedad para los que esa parte de la historia no es su historia? ¿Qué identidad están tejiendo ajenos a esos acontecimientos? La recuperación de la memoria debe servir para poner las cosas en su sitio, para acercarnos a la realidad, a toda la realidad, sin temer que nadie vaya a cortar lo que está brotando.

Una alumna de la asignatura sobre el exilio que impartí el curso pasado, escribía en el examen:

\begin{abstract}
Hay una idea que ha cambiado completamente en mí. Cuando intentaba pensar lo que era el exilio siempre pensaba en escritores que se habian ido de España para poder expresar sus ideas sin miedo alguno. Ahora me he dado cuenta que el exiliado es cualquier persona, no tiene por qué ser un intelectual del momento. La mayoría de los exiliados eran gentes completamente normales, personas de a pie, que no andaban de acuerdo con las ideas que les imponian. Estas personas renunciaron a su pais, a sus familias para poder vivir y pensar libremente. Lo que no podian imaginar era el dolor tan desgarrador que esto les supondría.
\end{abstract}

Otra alumna de la misma clase hacía este comentario en su examen:

Del exilio, a los de mi generación, no se nos ha hablado. Posiblemente hay quien lo descubrirá ahora, a través de un suplemento cultural (Exilio. País Semanal).

Leyendo yo hace unos años La voz dormida, novela de Dulce Chacón sobre las presas políticas en la inmediata posguerra (Chacón) me decía a mí mismo que el día que estalle este pasado en la sociedad española, ¿qué será de todos nosotros? Cuanto más nos alejamos de ese pasado, de sus monstruosos crimenes, resulta ese pasado criminal más horroroso; muchos de nosotros, que pertenecemos a otras generaciones posteriores y no hemos participado en ese pasado, nos vamos sintiendo, y lo somos, culpables. Porque hemos callado y el silencio nos vuelve moralmente cómplices y culpables... Hace poco decía Eduardo Haro Tecglen en su columna de El País:

Estamos en un momento más "histórico", si tenemos en cuenta los años transcurridos desde la última democracia real (1931-1936), y ahora por primera vez se advierte que la democracia está falsificada desde la transición, que a fin de cuentas fue un pacto de conveniencia y nada más entre un grupo de políticos atenazados por el miedo; y que esta democracia y esta idea de libertad ha caído vertiginosamente en los últimos tiempos, con un infantilismo que la aproxima mucho al de las dictaduras (Haro Tecglen). 
Ese diagnóstico hay que relacionarlo con lo que, con su pizca de ironía, cabría llamar efectos colaterales de la pérdida de la memoria histórica. El pacto de silencio sobre el que se armó el ingenio de la transición ha permitido que poco a poco se haya ido abriendo paso -primera gran efecto colateral de la pérdida de la memoria histórica- la tesis de que la actual democracia española es resultado del paternalismo benefactor de una dictadura, a la que todos Ilaman el "régimen anterior" y cuyas estatuas campean por sus anchas en las plazas y parques de casi toda España. Pues bien, la sociedad española, salvo algunas minorías que suelen coincidir con quienes han sido y en buena medida son aún poderes fácticos, tiene contraída ninguna deuda con el dictador. Al contrario, el dictador, vivo y muerto, ha sido un impedimento para que la sociedad española consiga recuperar el sistema de convivencia en libertad que los españoles se habían otorgado en tiempos de la segunda República. Tal es precisamente el argumento que apunta Haro Tecglen en su artículo y que Emilio Silva esboza en su ya citado artículo:

Se trata de llevar a cabo un debate que tras la muerte de Franco no se pudo hacer. Se trata de que la transición se convierta en lo que realmente se debió llamar y no se pudo pronunciar: una recuperación de la democracia que ya había llegado a España en noviembre de 1933, cuando votaron por primera vez las mujeres y los hombres con sufragio universal. También habrá que ver si ésa es una fecha que hay que celebrar, como lo hace cualquier democracia consolidada, o es mejor que siga habitando en la desmemoria colectiva.

Pero la derecha, que se ha aglutinado en ese partido de aluvión Ilamado PP, que fue creado sobre la marcha durante la primera transición, no es la única responsable de haber propiciado la desmemoria colectiva. Los partidos políticos que remontan sus orígenes al siglo XIX o a los albores del siglo XX, como es el caso del PSOE, el PCE o las distintas familias de los partidos republicanos, partidos y familias que auspiciaron la proclamación de la segunda República y tuvieron ya entonces representación parlamentaria, tienen su cota de responsabilidad en este presente español. Esa responsabilidad debe igualmente estudiarse y ventearse. Porque importa saber que no sólo se avinieron a firmar el pacto de silencio para conseguir la concordia nacional. Por mucho que se pretenda lo contrario, ése no fue el único motivo. Su connivencia con ese pacto tiene otros motivos y fines añadidos, tendentes todos a echar un velo sobre muchos errores políticos de los años de la República. Enumeraré, de manera muy sucinta, unos pocos: las luchas internas durante la guerra, la dimisión de Azaña, el golpe militar de Casado y Besteiro que precipitó la entrega de Madrid en marzo de 1939 y el final de la guerra, el complot de republicanos y prietistas contra el Dr. Negrín en la inmediata posguerra, los contubernios de Indalecio Prieto con don Juan de Borbón, eterno pretendiente al trono... (Caudet 1997, 207-243).

La dimisión de Azaña, el 27 febrero de 1939, y el golpe de Estado del coronel Casado, el 4 de marzo de 1939, acentuaron las divisiones que, desde los comienzos de la guerra, enfrentaban a los dirigentes políticos y militares del lado republicano. Además, esos dos acontecimientos pusieron en tela de juicio la legitimidad del gobierno de Negrín y, en última instancia, de las mismas instituciones republicanas. La dimisión de Azaña tuvo efectos especialmente negativos porque privó "a las fuerzas republicanas que seguian luchando en la zona Centro-Levante del estímulo principal para mantener la resistencia y creó serios problemas para cualquier intento de conservar la legitimidad de la República y sus instituciones una vez terminada la guerra" (Heine 1983, 29-30).

En cuanto a Casado, su golpe de Estado ahondó las muchas heridas abiertas en el Frente Popular durante la guerra que difícilmente llegaron, ni en los primeros meses del exilio ni con el paso del tiempo, a cicatrizar. Uno de los personajes de Campo del Moro, novela de Max Aub, decía que, al enterarse del golpe de Casado, lo que más quería era "la legitimidad..., lo único que puede salvar nuestro mundo carcomido".

A esa larga lista de errores sobre errores hay que sumar mezquinas luchas por el control político e ideológico dentro del PSOE que tuvieron gravísimas consecuencias. El ejemplo más terrible lo presenta el expolio del Vita por Indalecio Prieto. Amaro del Rosal, en su muy documentado estudio sobre el "tesoro del Vita", califica de "tercer golpe de Estado" contra la República la maniobra perpetrada en México por Indalecio Prieto. Según Amaro del Rosal: "El primer [golpe contra la República] fue el de Franco, el segundo el de Casado y el tercero el de Prieto..." (Del Rosal 151-152). En mis conversaciones con exiliados les he oído en varias ocasiones afirmar, siempre con un tono muy patético, que cuando Indalecio Prieto se apoderó del Ilamado "tesoro del Vita", la República sufrió la más terrible y abyecta derrota. 
El expolio del Vita condenó a miles de refugiados a no poder abandonar los campos de concentración en Francia y en el norte de África. Negrín había destinado ese tesoro para financiar el transporte de refugiados de Francia a México y a otros paises latinoamericanos. Para colmo de males, ese expolio atizó aún más las viejas querellas de prietistas y negrinistas. Negrín, y lo que representaba, debía desaparecer de la historia de la segunda República y del PSOE, partido al que pertenecian los dos... Prieto tenía ahora poder, gracias al dinero del Vita, para conseguir esa meta (Caudet 1997, 245-292).

En "El nuevo Tratado de París", uno de los ensayos recogidos en Hablo como hombre, sin fechar pero posiblemente escrito en 1960, lamentaba Max Aub los destructivos efectos de la desunión:

Toda nuestra razón se fue deshaciendo en el imbécil curso de nuestra emigración, a fuerza de vanidad, a fuerza de egolatria, al conjuro del egotismo de ese cura, y de aquel bandido, de la ineptitud de cada quisque, de la monstruosa vanidad de cualquier hijo de vecino, de la picardia de aquel arlequín y de la formidable capacidad para la incapacidad de tanto figurón tripudo, fuerza de amor propio, tan mal entendido que si de lo primero tiene poco de lo segundo se unta. La mezquindad y la ingratitud de Don Cómodo, la lentitud pancista, pro domo sua, los discursos interesados - pane lucrando- y al prójimo contra una esquina. ¿Para qué vamos a recordarlo?

Aquí se quedan los huesos y la sangre españoles inútilmente regados por las divergencias personales de cuatro perdidos. $Y$ digo perdidos en su sentido propio: "que no tiene o no lleva destino determinado" (Hablo como hombre, 197).

Las aguas del pasado bajan tan turbias por tantas torrenteras para que nadie, con independencia del partido a que pertenezca, tenga demasiado interés en que corran cristalinas, traslúcidas. No hay que rasgarse las vestiduras. Asi ha ocurrido en otros exilios (Pohle). Pero ese pasado de divisiones y de personalismos, de consecuencias tan graves para el conjunto del exilio, hay que dejar de minimizarlo, esconderlo o negarlo (Caudet 1997, 207-243).

El estudio del exilio debe llevarse a cabo -no hay otra via, no hay otra alternativa- sin anteojeras ideológicas. Hay que remover todas las aguas y todas sus pestilencias, estén donde estén y vengan de donde vengan aguas y pestilencias. Haremos un flaco favor al estudio del exilio si frente a quienes persisten en olvidar sus páginas menos aleccionadoras, optamos por dar una visión parcial y engañosa, falsa. Otra salida en falso es caer en su mitificación. Ya en 1983, en el prólogo a La oposición política al franquismo de Hartmut Heine, advertía Ángel Viñas sobre los peligros de continuar teniendo una visión mitificada, y por tanto distorsionada, del exilio. En ese prólogo escribía Ángel Viñas:

Los mitos no abundan sólo en la derecha. Un mérito innegable del presente libro es el demostrar cómo los errores de percepción y gestión, el peso de las divisiones del pasado, la pugna entre los líderes de los vencidos en la guerra civil, las ilusiones del exilio y las reyertas de personalidad contribuyeron, entre otros factores, a potenciar las consecuencias derivables de la contraposición de intereses, aspiraciones y métodos de los partidos que dieron soporte a la República derrotada (Heine 1983, 11).

El resultado de esa visión, que atañe a una pluralidad de ámbitos, conduce siempre a un resultado tergiversador y empequeñecedor. $Y$ ese resultado termina, en consecuencia, falseando los hechos. De ahí la necesidad, que para el estudio literario y cultural del exilio tiene capital importancia -por eso he vuelto a insistir en ello-, de no persistir en limitar el estudio del exilio a la creación literaria y artística, o a la obra en su sentido más amplio de los intelectuales, haciendo abstracción de que los escritores y artistas, o los intelectuales, no fueron los únicos exiliados es encerrar el concepto de cultura en el ámbito de las letras y las artes. Comparto, en suma, lo expresado más arriba por Ferrándiz Alborz, y más recientemente por Martínez Leal y Martínez Sáez, para quienes

explicar el exilio a través de la trayectoria de sus personajes relevantes, de su enorme proyección cultural en las Américas... es reduccionista, porque desde un punto de vista sociológico fue todo un pueblo el que emigró forzosamente al acabar la guerra civil. Visto desde esta perspectiva la historia del exilio debería abarcar, como quería Gramsci, "a todos los hombres, a tantos hombres como sea posible" (Girona 125).

El exilio republicano fue un fenómeno de masas. De masas que lucharon por la libertad y la justicia, por unas nuevas estructuras políticas y económicas, por acabar con las diferencias tan marcadas de clases, por la igualdad de 
oportunidades, por una sociedad y un Estado laicos... En una palabra, aquella España luchaba por la modernización del país. Ésa era, y es todavía en buena medida, una revolución pendiente en España.

Por tanto, ¿de qué hablamos, en esta hora de hoy, cuando hablamos del exilio literario republicano de 1939? ¿Se puede segregar esa literatura de esa revolución y del pueblo que por hacerla realidad luchó y sufrió toda suerte penalidades, la muerte y el exilio?

"Afán de justicia, eterno norte imaginario del hombre", llamó Max Aub en Campo de los almendros a esa lucha del pueblo español. Y en "Balance de un mundo perdido", recordando el 14 de abril de 1931, terminaba Max Aub su personal balance con estas palabras:

¡Qué pueblo! -exclamábamos [en abril de 1931]-. ¡Qué pueblo! En ello no nos equivocábamos: lo demostró cinco años más tarde. Los errores fueron otros (Hablo como hombre 256).

Existen ya muchos y muy valiosos estudios sobre el exilio (Abellán, Matesanz, Naharro, Rubio, Alted, Faber). Disponemos de obras sobre el exilio individuales y colectivas de enorme importancia. Merece los mayores encomios la labor desarrollada por el GEXEL. Hay que destacar, entre sus últimas actividades, la serie de doce congresos que bajo sus auspicios se celebraron en 1999, sesenta aniversario del final de la guerra y del comienzo del exilio, a lo largo y ancho del territorio español. De esos Congresos se han ido publicando todas las actas. También debemos al GEXEL la creación de la Biblioteca del Exilio.

No todos son motivos, pues, para el desaliento. Pero es necesario ya, a estas alturas, empezar a fijar nuevas metas y plantearse nuevas metodologías de trabajo.

Habría que crear, una tarea que debió haber iniciado el primer Gobierno de la democracia en 1977, la Biblioteca de la Memoria del Exilio (de los dos exilios: el exterior y el interior). Esa Biblioteca debería reunir todos los libros y toda la documentación sobre el exilio que se encuentra desperdigada en bibliotecas privadas y en las numerosas bibliotecas de Ateneos y agrupaciones republicanas de todos los paises que acogieron a exiliados. Y también debería reunir esa Biblioteca los testimonios personales, en forma de los más variados documentos: epistolarios, memorias inéditas, fotografías, libros de cuentas... La historia oral debería ser otro medio para recuperar, con la ayuda de personal y equipos especializados, los recuerdos de los supervivientes y los de sus familiares. Algo se ha hecho en este campo pero de manera deslavazada y discontinua (León-Portilla, Zelaya Kolker, Elena Aub).

El estudio del exilio requiere tomar en cuenta toda la documentación que se pueda salvar y recoger. Por desgracia, ya es tarde para salvarla toda; cada día que pasa es más imposible, es ya demasiado tarde. Pero hay que persistir, no cejar. $Y$ hacerlo a menudo con métodos de trabajo nada convencionales. Porque el tema, en extremo complejo, pone sobre las cuerdas a quienes se acercan a él con esquemas de análisis anclados en un academicismo estrecho de miras.

Es preciso partir del principio de que el estudio del exilio exige, más que ningún otro tema, amplitud de miras y muchas dosis de interdisciplinaridad. No hay una sola disciplina que sirva por si sola para su estudio. La antropología (Kenny) y la psiquiatría (Mental Health and Exile), así como la sociología o la historia oral, son disciplinas imprescindibles, entre otras muchas, para el estudio del exilio. Más que ningún otro tema, el estudio del exilio exige -no me canso nunca de insistir- la interdisciplinaridad. Hay que incorporar, por tanto, a los equipos que se ocupan principalmente del exilio literario especialistas de esas y otras disciplinas. Restringir el estudio del exilio, como se suele hacer, al análisis de sus obras literarias, artísticas o científicas, ha sido y es un grave error. Se explica porque somos de esos gremios. Pero el exilio es más, mucho más, que literatura, arte o ciencia.

El exilio es una subcultura que difícilmente se integra en la cultura del país de acogida (Matesanz; Caudet 1997). Este principio, que exige estudiarse tomando en cuenta todas sus variantes, ha de contribuir a rebatir las idealizaciones y tergiversaciones que han entronizado los conceptos de "transtierro" (Gaos) o el supuesto de que hay una identidad sin fisuras de lengua y cultura entre España y las repúblicas latinoamericanas de habla castellana (Matesanz; Caudet 1997: Faber).

Me mantengo firme en mi tesis de la necesidad de dialogizar el exilio. A ese tema he dedicado el capítulo diez de 
mi libro Hipótesis del exilio republicano de 1939 y con ese concepto sigo ocupándome en mis clases y en mis trabajos de investigación. Uno de los alumnos a los que me he referido ya escribía sobre esta cuestión en su examen:

A mi entender, dialogizar el exilio es algo muy productivo porque reviste a éste de una pluralidad de opiniones que, de otro modo, no se conseguirían. Le importa ángulos y voces que enriquecen a éste. Una sola opinión sobre un tema cualquiera, te da una visión limitada y hasta cierto punto poco objetiva, de este tema (en este caso del exilio). Por el contrario, una amplia gama de versiones legitimiza ese hecho. Adquiere carácter de realidad y le confiere objetividad. Dialogizar el exilio es atender a factores que hasta este momento se habian obviado. Tal es el caso de que al hablar del exilio se suele pensar en los muchos intelectuales que a pesar de haber sido desterrados, continuaron desde diversos campos de las artes (escritura, pintura, escultura, etc.) dando a conocer su dolor y sufrimiento. Éste es un factor determinante e importante del exilio republicano, pero no menos importante es el hecho de que aproximadamente el noventa y cinco por ciento de los exiliados eran trabajadores comunes (campesinos, obreros, etc.), que quizás por su naturaleza de trabajadores (y no pudiendo dedicarse a otras cosas) no son conocidos ni recordados, o tomados en cuenta. Son voces anónimas que mediante la dialogización del exilio se dan a conocer.

Tan importante es el testimonio de los escritores exiliados como el de estas almas anónimas, ya que todos sufrieron por igual, los escritores tuvieron la oportunidad de desahogarse en sus escritos y buscar algún alivio en las letras. Sin embargo, estos trabajadores no tuvieron esta válvula de escape y muchos de ellos se vieron rápidamente inmersos en una fuerza laboral ajena a la acostumbrada, alejados de su patria. Creo que ambas versiones del exilio se complementan y enriquecen el exilio proveyéndolo de diversos matices.

Otra manera de dialogizar el exilio es relacionar el exilio exterior y el interior. Porque uno y otro son dos caras, como decía más arriba, de la misma moneda, son dos partes de la misma historia.

La historia del exilio interior (Salabert; Ilie; Caudet 1998), cuyos capítulos más horribles tratan de cárceles, fusilamientos, enterramientos en fosas comunes, clandestinidad, torturas..., ponen nuevamente de manifiesto que intelectuales y pueblo corrieron una misma suerte (Torres; Casanova).
¿Bastará con recordar que Federico García Lorca está enterrado en una fosa común con otros muchos republicanos a los que mi estudiante llamaba, con espontánea ingenuidad, "almas anónimas"? Si, "almas anónimas", pero con nombre y apellidos, con familia, con un proyecto político que les costó la vida... Son todos parte de nuestro pasado tenebroso, son todos víctimas del genocidio franquista.

La recién creada Asociación para la Recuperación de la Memoria Histórica, y otros movimientos afines como "Amigos de los Caídos por la Libertad", piden que empiece la localización y la reapertura de las fosas comunes de los caídos por la libertad. Esas exigencias van acompañadas de la denuncia del silencio y olvido sobre los que se ha construido, como la asociación "Amigos de los Caídos por la Libertad" denuncia en uno de sus manifiestos, la entente política de la transición:

Aquellos políticos de la "transición", lisonjeados hoy por una artificiosa operación que pretende fabricar una Historia "políticamente correcta", y los líderes políticos de una amnésica izquierda parlamentaria, han permitido que esta ignominiosa capa de silencio envuelva la desaparición y ocultamiento en anónimas fosas comunes repartidas por toda España, de los cuerpos de miles de republicanos, hombres, mujeres y niños, civiles y militares, abonando las primaveras en las cunetas, en los prados y en pozos oscuros y recónditos.

La noticia que ha sacudido a la opinión pública española e internacional, de las acciones de localización y desenterramiento arqueológico que lleva a cabo desde hace unos meses la ARMH (Asociación para la Recuperación de la Memoria Histórica), con sede en Ponferrada (León), ha impactado por la dureza de la realidad criminal que descubren, poniendo al descubierto el auténtico rostro homicida del franquismo.

"Amigos de los Caídos por la Libertad" se manifiesta solidaria con la iniciativa que lleva a cabo en toda España la asociación ARMH de Ponferrada (León). Un trabajo titánico que ha encontrado su recompensa al hacer despertar en toda España el interés y la sensibilidad hacia este inmenso drama, que se convierte así en una irrecusable prueba de cargo contra el régimen del general Franco y sus cómplices.

Tras años de sufrir en silencio la ausencia de un ser querido, arrancado de la vida por la fuerza del odio y la sinrazón, han seguido años de callada angustia y tristeza, en unos casos por el sentimiento de saber el paradero de unos pobres huesos cubiertos de tierra y maleza en un lugar abandonado y anónimo; en otros, por haber venido arrastrando durante 
décadas el lacerante dolor de no saber su paradero, sin tener un lugar ante el que buscar consuelo, dejar unas flores, derramar unas lágrimas y evocar su recuerdo (www.fosas)

Finalmente, se añade en ese manifiesto la siguiente apostilla que nos atañe a los universitarios de manera muy especial:

No basta con recuperar unos huesos, con identificarlos, con tener un lugar donde honrarles y recordarles. Es preciso recuperar sus vidas, sus esperanzas en el proyecto de una España republicana abortado por la sublevación militar de 1936. La asociación quiere instar a las administraciones, a la Universidad, a los colectivos cívicos a llevar a cabo una operación multidisciplinar para que nada se pierda: los testimonios, los documentos, la geografía de aquel genocidio: fosas, arquitectura carcelaria o relacionada con ella, etc. Todos estos elementos, debidamente conservados deben servir para componer lecciones de historia, de vida y de formación en ideales de solidaridad, pacifismo y tolerancia.
En suma, y como conclusión, albergo el temor de que se caiga en el grave error de introducir el exilio en el canon de la historiografía literaria de la España de posguerra. Ello equivaldría a su "normalización", palabra tan cercana al concepto "Gleichschaltung", tan del gusto de Hitler y -imenuda ironía!- de muchos nacionalistas de esta hora democrática española. Sería -insisto- un grave error. E exilio, que no se puede "normalizar", no es un capítulo más de la historia literaria. Es otra cosa. Es un capítulo del pasado español que debe seguir situado fuera, para desde fuera mirar hacia dentro.

Tampoco esos muertos de las fosas comunes pueden ser enterrados, piensan muchos de sus familiares, en los cementerios de las ciudades españoles donde habrían sido enterrados si hubieran muerto de muerte natural. Tienen que dar testimonio, desde las fosas comunes, del horror. Pero para ello hay que saber el lugar donde están esas fosas. Se trata de la dignidad de las víctimas y de sus familiares. Y de la sociedad española en su conjunto.

\section{BIBLIOGRAFÍA}

Recibido: 16 de febrero de 2008 Aceptado: 23 de abril de 2009
Peter Brooks, en Psychoanalysis and Literature.

Abellán, José L. (ed.) (1976-1978): El exilio español de 1939, 6 vols. Madrid: Taurus.

Alba, Victor (1978): Historia de la resistencia antifranquista, Barcelona: Planeta.

Aub, Elena (1992): Palabras del exilio. Historia del ME/59. Una última ilusión, México, D.F.: Consejo Nacional para la Cultura y las Artes, Instituto Nacional de Antropología e Historia (INAH).

Aub, Max (2002): Hablo como hombre, Ed. Gonzalo Sobejano, Segorbe: Biblioteca Max Aub.

Ayala, Francisco (1981): "La cuestionable literatura del exilio". Los Cuadernos del Norte núm. 8, julio-agosto.

Aznar Soler, Manuel (ed.) (1998): El exilio literario español de 1939, I-II, BarceIona, Gexel.

Balfour, Sebastian (2002): Abrazo moratl. De la guerra colonial a la Guerra Civil en España y Marruecos (1909-1939), Barcelona: Península.

Barrero Pérez, Óscar (1987): La novela existencial española de posguerra. Madrid: Gredos.

Berger, John (1979): Ways of seeing, London: Penguin Books.

- y Jean Mohr (1995): Another way of telling, New York: Vintage.

Bolinger, Dwight L. (1953): "...And should thereby be judged", Books Abroad, 27, 2, Spring, 129-132.

Brodsky, Joseph (1995): Menos que uno, Barcelona: Altaya.

- $\quad$ (1988): "The condition we call exile". The New York Review of Books, 21 enero.

- (1949): "Para quién escribimos nosotros", Cuadernos Americanos, núm. 43, enero-febrero, 36-58 
Casanova, J. (coord.) (2002): Morir, matar, sobrevivir. La violencia en la dictadura de Franco, Barcelona: Crítica.

Caudet, Francisco (1999): "Mirando en la memoria las señales", Ínsula, núm. 627, marzo, 18-20.

- (1984): Crónica de una marginación. Conversaciones con Alfonso Sastre, Madrid: Ediciones de la Torre.

- (1992): El exilio español en México. Las revistas literarias (1939-1971), Madrid: Fundación Banco Exterior.

- (1992): El exilio republicano en México. Las revistas literarias, 1939-1971, Prólogo de Manuel Tuñón de Lara. Madrid: Fundación Banco Exterior.

- (2002): El parto de la modernidad. La novela española de los siglos XIX-XX, Madrid: Ediciones de la Torre.

- (1997): Hipótesis sobre el exilio republicano de 1939, Prólogo de Alicia Alted Madrid: Fundación Universitaria Española.

- (1998): Introducción a Juan Hermanos. El fin de la esperanza, Madrid: Tecnos, 1998, pp. 9-72.

Chacón, Dulce (2002): La voz dormida, Madrid: Alfaguara.

Domínguez Prats, Pilar (1994): Voces del exilio. Mujeres españolas en México (1939-1950), Madrid: Comunidad de Madrid, Dirección General de la Mujer.

Dreyfus-Armand, G. (1996): "La guerra y la resistencia en Francia", Memoria del olvido. La contribución de los republicanos españoles a la Resistencia y a la Liberación de Francia, París: FACEEF.

El destierro español en América. Un trasvase cultural, N. Sánchez-Albornoz, ed. Madrid: Ediciones Siruela, 1994. El destierro español en América. Un trasvase cultural, Madrid, Ediciones Siruela, 1994.

El exilio español en México (1939-1982), México: Fondo de Cultura Económico, 1982.
El exilio español en México 1939-1982, México, D.F.: Salvat-Fondo de Cultura Económica, 1982.

Españoles en Francia. 1936-1946, Salamanca, Universidad, 1991.

Exilio. La historia olvidada. El País Semanal, 12 de enero de 2003.

Faber, Sebastian (2002): Exile and Cultural Hegemony. Spanish Intellectuals in Mexico, 1838-1975, Nashville: Vanderbilt University Press.

Fagen, Patricia W. (1975): Transterrados y ciudadanos. Los republicanos españoles en México, México, D.F.: Fondo de Cultura Económica.

Ferrándiz Alborz, F. (1957): "¿Qué será de España?", España Republicana (Buenos Aires), 30 de agosto.

Fontana, Josep (1986): "Reflexiones sobre la naturaleza y las consecuencias del franquismo", en J. Fontana (ed.), España bajo el franquismo. Barcelona: Crítica.

Fusi, J. P. y Palafox, J. (1997): España: 1801-1996. El desafío de la modernidad, Madrid: Espasa Calpe, 2. ${ }^{\text {a ed. }}$

Gaos, José (1947): "Los "transterrados" españoles de la filosofía en México", Filosofía y Letras, 36, octubre-diciembre, 225-226.

Garcia de la Concha, Víctor (1973): La poesia española de posguerra, Madrid: Prensa Española.

Grass, Günter (1999): Artículos y ensayos, Barcelona, Círculo de Lectores.

Fuentes, Carlos (1988): "La lliada descalza", nota liminar a Juan Rulfo, Los de abajo, ed. J. Ruffinelli, París, UNESCO.

Guillén, Claudio (1995): El sol de los desterrados: literatura y exilio, Barcelona: Sirmio/Quaderns Crema.

Haro Tecglen, Eduardo (2003): "Cambia la pequeña historia", El País, 4 de febrero.

Heine, Hartmut (1990): "Tipología y caracteristicas de la represión y violencia políticas durante el período 1939-
1961", en J. Tusell, A. Alted y A. Mateos (coord.), La oposición al régimen de Franco, I, Madrid: UNED, p. 309.

Ilie, Paul (1981): Literatura y exilio interior, Madrid: Fundamentos.

Iturralde, J. de (1965): El catolicismo y la cruzada de Franco, III, Toulouse: PU.

Jáuregui, Fernando y Pedro Vega (1983): Crónica del antifranquismo, I, BarceIona: Argos Vergara.

Kenny, Michael (1962): "Twentieth-century Spanish Expatriates in Mexico: an urban Sub-culture", Anthropological Quarterly, 35, octubre.

León-Portilla, Ascención H. de (1978): España desde México. Vida y testimonio de transterrados, México: Universidad Nacional Autónoma de México.

Linz, J. (1974): "Una teoria del régimen autoritario. El caso de España", en M. Fraga, J. Velarde y S. del Campo (eds.), La España de los años setenta. III. El Estado y la Política. Madrid: Moneda y Crédito.

Lledó, Emilio (1992): El surco del tiempo. Barcelona: Crítica, 2. ${ }^{\text {a }} \mathrm{ed}$.

- (1994): Memoria de la ética, Madrid: Taurus.

Llorens, Vicente (1967): "El retorno del desterrado", en Literatura, historia, politica, Madrid, Revista de Occidente.

Manuel Tuñón de Lara: El compromiso con la Historia. Su vida y su obra. ed. J. L. de la Granja y A. Reig Tapia. Bilbao: Universidad del País Vasco, 1993.

Marra-López, José Ramón (1963): Narrativa española fuera de España (19391961), Guadarrama: Madrid.

Martínez Cachero, J. M. ${ }^{a}$ (1997): La novela española entre 1936 y el fin de siglo. Historia de una aventura, Castalia, Madrid.

- (1945): Novelistas españoles de hoy, Oviedo.

Martínez Leal, J. y Martínez Sáez, F. (1995): "Alicantinos en el exilio americano", A. Girona y M. ${ }^{a}$ F. Mancebo (eds.), El 
exilio valenciano en América. Obra y memoria, Valencia: Instituto de Cultura Juan Gil-Albert/Universitat de Valencia.

Mateo Gambarte, Eduardo (1996): Literatura de los "niños de la guerra" del exilio español en México, Lérida, Spain: Universitat de Lleida, Pages Editors.

Matesanz, José Antonio (1999): Las raíces del exilio. México ante la Guerra Civil Española, 1936-1939, México, D.F.: Colegio de México, Universidad Nacional Autónoma de México.

Mental Health and Exile: Papers Arising From a Seminar on Mental Health and Latin American Exiles. London: World University Service, 1981.

Molina, Juan Manuel (1976): El movimiento clandestino en España (19391949), México: Editores Mexicanos Reunidos.

Morán, Fernando (1971): Explicación de una limitación, la novela realista de los años cincuenta en España, Madrid: Taurus.

- (1971): Novela y semidesarrollo (Una interpretación de la novela hispanoamericana y española), Madrid: Taurus.

Naharro-Calderón, José M. ${ }^{a}$ (ed.) (1991): El exilio de la España de 1939 en las Américas, Barcelona, Anthropos.

- (1994): Entre el exilio y el interior: el "entresiglo" y Juan Ramón Jiménez, Barcelona: Anthropos.

Navarro, Vicenç (2002): Bienestar insuficiente, democracia incompleta. Sobre lo que no se habla en nuestro país, Barcelona: Anagrama.

Pensamiento español contemporánea y la idea de América, J. L. Abellán y A.
Monclús (eds.). Barcelona: Anthropos, 1989.

Pla Brugat, Dolores (1994): "Caracteristicas del exilio en México en 1939", en Una inmigración privilegiada. Comerciantes, empresarios y Profesionales españoles en México en los siglos XIX y XX, ed. Clara E. Lida, 218-31- Madrid: Alianza.

Pohle, Fritz (1986): Das Mexikanische Exil. Ein Beitrag zur Geschichte der politisch-kulturellen Emigration aus Deutschland (1937-1946), Stuttgart: J. B. Metzler.

Preston, Paul (ed.) (1978): España en crisis. Evolución y decadencia del régimen de Franco, México: FCE.

Reig Tapia, Alberto (1984): Ideología e historia (Sobre la represión franquista y la guerra civil), Madrid: Akal.

Rodríguez Puértolas, Julio (1986): Literatura fascista española, 2 vols., Madrid: Akal.

Rosal, Amaro del (1977): El oro del Banco de España y la historia del Vita, BarceIona: Grijalbo.

Rubio, Javier (1977): La emigración de la guerra civil de 1936-1939, 2 vols., Madrid: Editorial San Martín.

Salabert, M. (1988): El exilio interior, BarceIona: Anthropos (1. a ed, París, 1961).

Salas Larrazábal, Ramón (1980): Los datos exactos de la guerra civil, Madrid: Rioduero.

- (1977): Pérdidas de la guerra. BarceIona: Planeta.

Salaün, Serge (1985): La poesía de la guerra de España, Madrid: Castalia.

Sanz Villanueva, Santos (1980): Historia de la novela social española (1942-1975), Madrid, Alhambra, 2 vols.
Silva, Emilio (2002): "Las tareas pendientes", El País, 15 de diciembre.

Sobejano, Gonzalo (1970): Novela española de nuestro tiempo (en busca del pueblo perdido), Madrid, Prensa Española.

Soldevila Durante, Ignacio (1980): La novela desde 1936, Madrid, Alhambra.

Soriano, A. (1989): Éxodos. Historia oral del exilio republicano en Francia 19391945, Barcelona: Crítica.

Steiner, G. (1977): Extraterritorial. Papers on literature and language revolution, New York, Atheneum.

Sueiro, Daniel (1983): El Valle de los Caídos. Los secretos de la cripta fran-

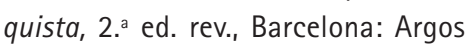
Vergara.

Tcach, C. y Reyes, C. (1986): Clandestinidad y exilio. Reorganización del sindicato socialista. 1939-1953, Madrid: Editorial Pablo Iglesias.

Torres, Rafael (2000): Los esclavos de Franco, Madrid: Oberón.

Tusell, Javier (1975): La España del siglo XX. Desde Alfonso XIII a la muerte de Carrero Blanco, Barcelona: Dopesa.

Tusell, J.; Alted, A. y Mateos, A. (coord.) (1990): La oposición al régimen de Franco, 3 vols., Madrid: UNED.

Ugarte, M. (1989): Shifting ground Spanish civil war exile literature, Durham: Duke University press.

Vernant, Jacques (1953): The Refugee in the Post-War World, New Haven: Yale University Press.

www.fosas

Zelaya Kolker, Marielena (1985): Testimonios americanos de los escritores transterrados de 1939, Madrid: Cultura Hispánica. 